\title{
Imaging dose and secondary cancer risk in image-guided radiotherapy of pediatric patients
}

Yvonne Dzierma*, Katharina Mikulla, Patrick Richter, Katharina Bell, Patrick Melchior, Frank Nuesken and Christian Rübe

\begin{abstract}
Background: Daily image-guided radiotherapy (IGRT) can contribute to cover extended body volumes with low radiation dose. The effect of additional imaging dose on secondary cancer development is modelled for a collective of children with Morbus Hodgkin.

Methods: Eleven radiotherapy treatment plans from pediatric patients with Hodgkin's lymphoma were retrospectively analyzed, including imaging dose from scenarios using different energies (kV/MV) and planar/cone-beam computed tomography (CBCT) techniques. In addition to assessing the effect of imaging dose on organs at risk, the excess average risk (EAR) for developing a secondary carcinoma of the lung or breast was modelled.

Results: Although the variability between the patients is relatively large due to the different target volumes, the additional EAR due to imaging can be consistently determined. For daily $6 \mathrm{MV} \mathrm{CBCT,} \mathrm{the} \mathrm{EAR} \mathrm{for} \mathrm{developing} \mathrm{a} \mathrm{secondary}$ cancer at age 50 is over 3 cases per $10^{4} \mathrm{PY}$ (patient-years) for the female breast and $0.7-0.8$ per $10^{4} \mathrm{PY}$ for the lungs. This can be decreased by using only planar images ( $<1$ per $10^{4} \mathrm{PY}$ for the breast and 0.1 for the lungs). Similar values are achieved by daily $360^{\circ} \mathrm{kV}$ CBCT (0.44- 0.57 per $10^{4} \mathrm{PY}$ for the breast and 0.08 per $10^{4} \mathrm{PY}$ for the lungs), which is again reduced for daily $200^{\circ} \mathrm{kV} \mathrm{CBCT}$ ( 0.02 per $10^{4} \mathrm{PY}$ for the lungs and $0.07-0.08$ per $10^{4} \mathrm{PY}$ for the breast). These values increase if an older attained age is considered (e.g., for 70 years, by a factor of four for the lungs).

Conclusions: Daily imaging can be performed with an additional secondary cancer risk of less than 1 per $10^{4} \mathrm{PY}$ if $\mathrm{kV}$ CBCT is applied. If MV modalities must be chosen, a similar EAR can be achieved with planar images. A further reduction in risk is possible if the imaging geometry allows for sparing of the breast by a partial rotation underneath the patient.
\end{abstract}

Keywords: Secondary cancer risk, Radiotherapy for Hodgkin lymphoma, Image-guided radiotherapy, Imaging dose in pediatric patients

\section{Background}

Modern radiotherapy offers ever improved techniques for optimal target coverage associated with utmost sparing of neighbouring tissues and organs at risk (OAR's). As dose conformity and dose gradients are increasing, image-guided radiotherapy (IGRT) is a prerequisite, and frequent to daily image-guided positioning verification is common. Since most IGRT systems rely on ionizing radiation for EPID-based (electron portal imaging device) projection or cone-beam computed tomography (CBCT)

* Correspondence: Yvonne.dzierma@uks.eu

Department of Radiotherapy and Radiation Oncology, Saarland University Medical Centre, Kirrberger Str. Geb. 6.5, 66421 Homburg, Saar, Germany imaging, an evaluation of the contribution of imaging dose to the treatment plan should be performed, and has been presented for a number of indications in the recent literature. This need is particularly pronounced since there exists a variety of different imaging systems using different photon energy ( $\mathrm{kV}$ or MV), with 2D or 3D imaging, the dose of which is generally not included in the treatment planning system (TPS). While it is undisputed that the general benefit of image-guided positioning surmounts the possibly deteriorating effects of additional imaging dose on plan quality, particularly sensitive patient collectives such as pediatric patients with good prognosis should not receive excessive imaging dose to

(C) The Author(s). 2018 Open Access This article is distributed under the terms of the Creative Commons Attribution 4.0 International License (http://creativecommons.org/licenses/by/4.0/), which permits unrestricted use, distribution, and 
avoid OAR complications or - in the even lower dose regime - risk of developing secondary malignancies.

The aim of this study is therefore to analyse and compare several common linac-based imaging scenarios (6MV and $121 \mathrm{kV}$ energies for planar and CBCT imaging with daily or non-daily frequency) with regard to their influence on OAR dose and secondary cancer risk in children with Morbus Hodgkin irradiated at the Saarland University Medical Centre. This collective was chosen because of good long-term survival of children with Hodgkin's lymphoma, so that there is a high probability that they will live long enough so that a secondary cancer might develop. Furthermore, secondary cancer induction by irradiation of Morbus Hodgkin patients has been extensively studied for the same reason, so that mathematical model parameters for secondary cancer risk are better known for this type of irradiation.

To assess imaging dose contribution, the summation dose from the complete treatment including different imaging scenarios is calculated and secondary cancer risk is estimated. Although other studies have previously estimated secondary cancer risk for the irradiation of children, they have mainly concentrated on the imaging dose or treatment dose separately. This approach is problematic since the secondary cancer risk from these two contributions cannot be expected to be additive - in fact, the secondary cancer risk estimated for imaging dose would normally use a linear model, which only applies in the low-dose regime. Conversely, the secondary cancer risk model for higher doses of the order of a radiotherapy treatment protocol is generally expected to fall out of the linear range, where either bell-shaped or plateau-like models are assumed to account for cell sterilization. In these cases, adding a linearly estimated secondary cancer risk from imaging dose to the risk calculated for the treatment plan separately might yield quite a different result than directly estimating the total risk from the combined dose distribution. A priori, it cannot be known how the two effects interact, which will also be discussed in this study.

\section{Methods}

\section{Patient collective}

We included in the analysis all children treated for Hodgkin's lymphoma at the Department of Radiotherapy and Radiation Oncology, Saarland University Medical Centre, in the years 2011 through 2015, which are seven children aged 5-17 years (mean age 14 years) with 11 different target sites (analysed separately, see Table 1 for details). After obtaining written informed consent of the patients and the patients' parents, the patients received involved-field irradiation with 19.8-29.8 Gy in fractions of 1.0-1.8 Gy using an intensity modulated radiotherapy technique (IMRT) with $6 \mathrm{MV}$ photons. In total 134 treatment fractions were delivered, with image-guidance in 63 fractions.
For image-guidance, the following systems are available at our department:

1. $6 \mathrm{MV}$ treatment beam (TBL) at two Siemens Artiste and one Siemens Oncor (Siemens Healthcare, Erlangen, Germany) linear accelerators,

2. $1 \mathrm{MV}$ image beam line (IBL) at two Siemens Artiste linear accelerators [1-3], and

3. $121 \mathrm{kV}$ system kVision at one Siemens Artiste linear accelerator [4-7].

All systems can be used to acquire planar or CBCT images. Planar MV axial images are taken using 1 monitor unit (MU) each from two orthogonal views. For MV CBCT images, either a full $360^{\circ}$ or a shortened arc $\left(200^{\circ}\right)$ can be used with different MU settings depending on the patient anatomy and geometry (7-11 MU), with a square field of $27.4 \mathrm{~cm}$ width at source-to-surface distance (SSD) $100 \mathrm{~cm}$ [1]. The kVision system applies a "pre-shot" to automatically optimize the exposure (the $\mathrm{mAs}$ value is displayed and protocolled, generally less than $10 \mathrm{mAs}$ for planar images and between 200 and $700 \mathrm{mAs}$ for CBCT in our collective). While the MV $\mathrm{CBCT}$ gantry rotates above the head of the patient, the $\mathrm{kV} \mathrm{CBCT}$ geometry with a reduced arc is inverted, rotating below the back of the patient because the X-ray tube is installed opposite the treatment head. The field size at SSD $100 \mathrm{~cm}$ is $28 \times 28 \mathrm{~cm}^{2}$ for the $\mathrm{kV}$ system [4].

The realistic imaging scenarios applied for the patients depended to some degree on the availability of the techniques for imaging - in 2011, only the $6 \mathrm{MV}$ energy was available, the $\mathrm{kVision}$ system was installed last (end 2012). When available, the lower-energy systems were preferentially used for imaging; the percentage use of each imaging system is shown in Fig. 1a. A no-action-level protocol of online positioning correction was followed, so that all deviations observed in pre-treatment imaging (unless smaller than $1 \mathrm{~mm}$ ) were always corrected for. An analysis of the performed couch shifts after imaging (Fig. 1b) agrees with a normal distribution, although the patient collective is too small to allow for statistical significance. It was checked in a phantom study that the different imaging modalities are in agreement regarding the detected positioning errors [8].

\section{Dose calculation and secondary cancer risk model}

The three imaging systems are all commissioned in the Philips Pinnacle treatment planning system (Philips Healthcare, Koninklijke, Netherlands) [1, 4, 9], so that the imaging dose can be calculated together with the patient treatment plan. For each patient, the dose distribution of the original treatment plan (as it was accepted for treatment $=$ Scenario 1 ) without inclusion of imaging dose is compared with the following imaging scenarios: 
Table 1 Patients and target volumes analysed. PTV: planning target volume

\begin{tabular}{|c|c|c|c|c|c|}
\hline Case & Patient & $\begin{array}{l}\text { Age at } \\
\text { treatment }\end{array}$ & PTV & Prescription & Imaging \\
\hline 1 & 1 & 16 & $\begin{array}{l}\text { 1st series: right lung; } \\
\text { 2nd series: right lung and infraclavicular/ } \\
\text { pectoral/ mediastinal lymphatics }\end{array}$ & $\begin{array}{l}\text { 1st series: } 3 \times 100 c G y ; \\
\text { 2nd series: } 11 \times 100 \mathrm{cGy} ; \\
\text { 11x166cGy }\end{array}$ & $\begin{array}{l}1 \times 6 \mathrm{MV} \text { axes } \\
11 \times \mathrm{IBL} \text { axes }\end{array}$ \\
\hline 2 & 2 & 15 & $\begin{array}{l}\text { bilateral neck cervical, supra- and infraclavicular } \\
\text { lymphatics and mediastinum }\end{array}$ & 11x180cGy & $\begin{array}{l}1 \times 6 \mathrm{MV} \text { axes } \\
3 \times \mathrm{IBL} \text { axes }\end{array}$ \\
\hline 3 & 3 & 17 & Right cervical/mediastinal lymphatics & 11x180cGy & $\begin{array}{l}4 \times 6 \mathrm{MV} \text { axes } \\
1 \times 6 \mathrm{MV} \text { CBCT }(7.2 \mathrm{MU})\end{array}$ \\
\hline 4 & 4 & 16 & $\begin{array}{l}\text { 1st series: Mediastinum } \\
\text { 2nd series: Boost Mediastinum }\end{array}$ & $\begin{array}{l}\text { 1st series: } 11 \times 180 c G y ; \\
\text { 2nd series: } 5 \times 200 c G y\end{array}$ & $\begin{array}{l}1 \times 6 \mathrm{MV} \text { axes } \\
4 \times \mathrm{IBL} \text { axes }\end{array}$ \\
\hline 5 & 4 & 16 & Spleen & 11x180cGy & $\begin{array}{l}1 \times 6 \mathrm{MV} \text { axes } \\
4 \times \mathrm{IBL} \text { axes }\end{array}$ \\
\hline 6 & 5 & 16 & $\begin{array}{l}\text { 1st series: Mediastinum; } \\
\text { 2nd series: Boost macroscopic residual disease } \\
\text { (Mediastinum) }\end{array}$ & $\begin{array}{l}\text { 1st series: } 11 \times 180 c G y ; \\
\text { 2nd series: } 5 \times 200 c G y\end{array}$ & $\begin{array}{l}6 \times \mathrm{kV} \text { axes } \\
1 \times \mathrm{kV} \text { CBCT (414 mAs) }\end{array}$ \\
\hline 7 & 5 & 16 & Spleen & 11x180cGy & $\begin{array}{l}1 \times 6 \mathrm{MV} / \mathrm{IBL} \text { axes } \\
1 \times \mathrm{kV} \text { axes } \\
1 \times \mathrm{kV} \text { CBCT }(621 \mathrm{mAs})\end{array}$ \\
\hline 8 & 6 & 5 & $\begin{array}{l}\text { bilateral neck, supra-infraclavicular, mediastinal } \\
\text { and paraaortic lymphatics, spleen }\end{array}$ & 11x180cGy & $\begin{array}{l}3 \times 6 \mathrm{MV} \text { axes } \\
5 \times 6 \mathrm{MV} \text { CBCT ( } 54 \mathrm{MU} \text { in total) }\end{array}$ \\
\hline 9 & 6 & 5 & Os ileum & $11 \times 180 c G y$ & $5 \times 6 \mathrm{MV}$ portal images \\
\hline 10 & 7 & 13 & Left cervical lymphatics & $11 \times 180 c G y$ & $\begin{array}{l}1 \times \mathrm{kV} \text { axes } \\
2 \times \mathrm{kV} \text { CBCT ( } 458 \mathrm{mAs} \text { in total) }\end{array}$ \\
\hline 11 & 7 & 13 & Spleen & 11x180cGy & $\begin{array}{l}2 \times \mathrm{kV} \text { axes } \\
3 \times \mathrm{kV} \text { CBCT }(1103 \mathrm{mAs} \text { in total }) \\
1 \times \operatorname{IBL} \mathrm{CBCT}(11 \mathrm{MU})\end{array}$ \\
\hline
\end{tabular}

- Scenario 2: treatment plan with real imaging performed for the patient, with imaging device and frequency differing between the individual patients (details listed in Table 1)

- Scenario 3: treatment plan with daily $121 \mathrm{kV} 200^{\circ} \mathrm{CBCT}$

- Scenario 4: treatment plan with daily $121 \mathrm{kV} \mathrm{360^{ \circ } \mathrm { CBCT }}$

- Scenario 5: treatment plan with daily $6 \mathrm{MV}$ planar imaging

- Scenario 6: treatment plan with daily $360^{\circ} 6 \mathrm{MV}$ CBCT.

The hypothetical scenarios 3-6 are chosen to analyse the effect of daily imaging, which is more and more becoming the norm [10]. For the $\mathrm{kV}$ and $6 \mathrm{MV} \mathrm{CBCT}$ scenarios, the average mAs or MU per rotation was calculated for all patients and applied for the hypothetical scenarios: $360^{\circ} \mathrm{kV} \mathrm{CBCT}$ with $377 \mathrm{mAs}, 200^{\circ} \mathrm{kV} \mathrm{CBCT}$ with $99 \mathrm{mAs}, 6 \mathrm{MV} \mathrm{CBCT}\left(360^{\circ}\right)$ with $11 \mathrm{MU}$. Evidently, $\mathrm{kV}$ imaging is the most desirable scenario; however, this is not available at every clinic. This is why we include $6 \mathrm{MV}$ imaging to see how daily imaging can be achieved if only this modality is available. While it is clear that daily $6 \mathrm{MV}$ CBCT would entail too high imaging dose, we include this scenario as the maximum possible imaging dose; contrarily, daily planar images with $6 \mathrm{MV}$ are included as example of the lowest achievable imaging dose for daily MV images. Reality will range in between these two scenarios as occasional CBCT may be used to acquire $3 \mathrm{D}$ views. As $\mathrm{kV}$ planar images involve very little dose in comparison with all other modalities (lower than $\mathrm{kV} \mathrm{CBCT}$ or planar MV images by at least an order of magnitude), this modality is not included in our analysis.

Dose calculation of the summation plans was carried out in the Philips Pinnacle TPS Version 9.0-9.6 on a $2 \mathrm{~mm}$ dose grid using the collapsed cone algorithm (for a detailed explanation of the procedure, compare [11]). Dose-volume histogram (DVH) values are considered to assess dose to the organs at risk (OARs). For secondary cancer risk calculation, the dose distribution was exported together with the regions of interests (ROIs) of the OARs and imported into Matlab R2015a (MathWorks, Natick, Massachusetts, USA). An in-house software was created to calculate the organ-specific risk for developing secondary carcinoma using Schneider's mechanistic model [12]. This gives the organ excess absolute risk as

$$
E A R_{\text {org }}\left(a g e_{x}, a g e_{a}\right)=\beta_{\text {org }} \cdot O E D \cdot \mu\left(a g e_{x}, a g e_{a}\right),
$$

where $a g e_{x}$ and $a g e_{a}$ are the age at exposure and age attained (when developing the secondary malignancy), respectively, 

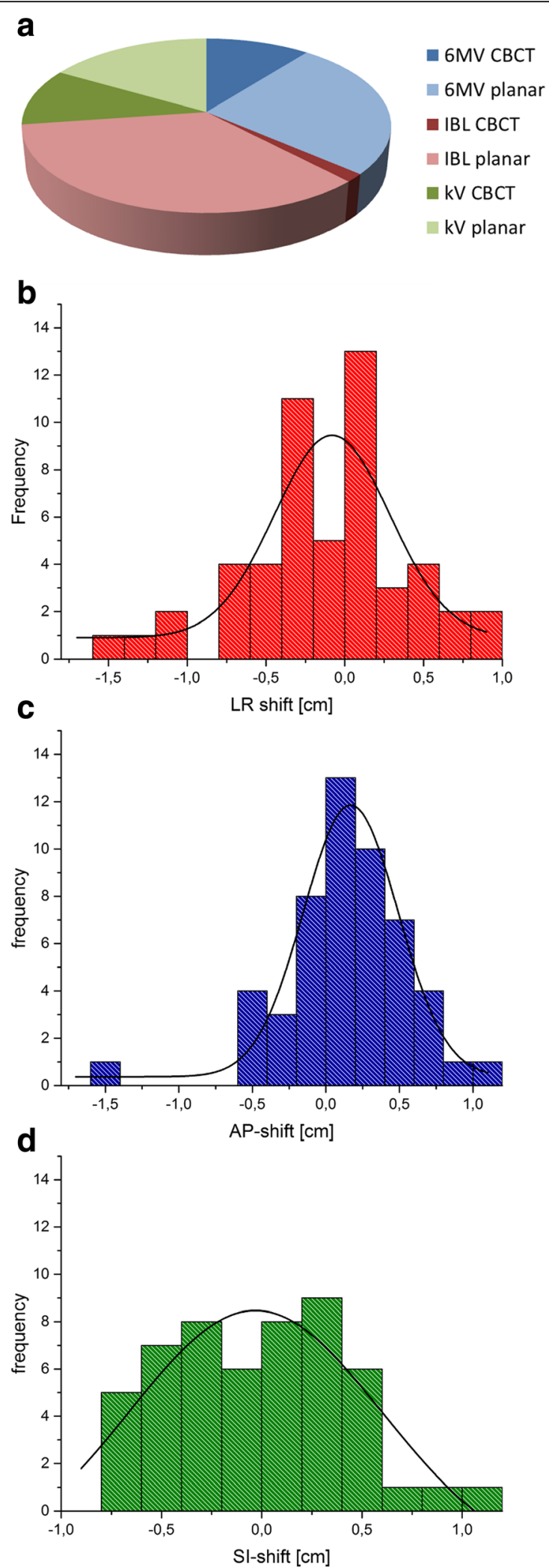

Fig. 1 a Percentage use of each imaging modality in the patient collective. b Frequency distribution of couch shifts in left-right (LR), (c) anterior-posterior (AP) and (d) superior-inferior (SI) direction

$$
\mu\left(\text { age }_{x}, \text { age }_{a}\right)=\exp \left(\gamma_{e}\left(a g e_{x}-30\right)+\gamma_{a} \ln \frac{a g e_{a}}{70}\right)
$$

is a modifying function for adjusting the risk to the ages $a g e_{x}$ and $a g e_{a}$ and $\beta$ is a model scaling parameter between the organ effective dose (OED) and the EAR. The organ effective dose is calculated according to [12] as the risk-equivalent-dose (RED)-weighted average of the total volume $V_{T}$

$$
O E D=\frac{1}{V_{T}} \cdot \sum_{i} V\left(D_{i}\right) R E D\left(D_{i}\right),
$$

with the organ-specific dose-response relationship given by the mechanistic model for carcinoma induction including cell killing and fractionation effects:

$$
R E D(D)=\frac{\exp \left(-\alpha^{\prime} D\right)}{\alpha^{\prime} R}\left(1-2 R+R^{2} \exp \left(\alpha^{\prime} D\right)-\left(1-R^{2}\right) \exp \left(-\frac{\alpha^{\prime} R}{1-R}\right) D\right) .
$$

Fractionation is taken into account using the linear quadratic model with parameters $\alpha$ and $\beta$ and a fractionation with target volume prescribed dose $D_{T}$ in fraction doses of $d_{T}$ :

$$
\alpha^{\prime}=\alpha+\beta d=\alpha+\beta \frac{D}{D_{T}} d_{T} .
$$

The main two organs at risk for secondary cancer development in our patient collective are the lungs and the breast, for which the model parameters are given in Table 2.

The software uses the DICOM (Digital Imaging and Communications in Medicine) structure sets, RT dose and $\mathrm{CT}$ data set as input together with the organ specific model parameters to calculate the excess absolute cancer risk. In each case, the age of the patient at exposure was included; the secondary cancer risk was modelled for an attained age of 50 years.

A statistical analysis was carried out in Origin Pro 2015G (OriginLab, Northampton, Massachusetts, USA) for descriptive statistics. To assess differences between the planning scenarios, the plans were pair-wise compared against the original plan ("gold standard" without imaging dose) using the Wilcoxon signed-rank test. Please note that "gold standard" is taken to mean the optimal dose distribution (no deterioration from imaging

Table 2 Parameters for modelling the excess absolute risk (from [12])

\begin{tabular}{lll}
\hline Model parameter & Female breast & Lung \\
\hline$a$ in $\mathrm{Gy}^{-1}$ & 0.044 & 0.042 \\
$\mathrm{R}$ & 0.15 & 0.83 \\
$\beta_{\text {org }}$ in excess cases per 10,000 PY Gy & 8.2 & 8.0 \\
$Y_{e}$ & -0.037 & 0.002 \\
$Y_{a}$ & 1.7 & 4.23 \\
\hline
\end{tabular}


dose), as it was accepted for treatment - this is not suggested as the optimal verification scenario, just as a baseline for dose comparisons (see Discussion).

\section{Results}

\section{Visualization of dose distributions - Example}

Figure 2 shows an example of the imaging dose distribution and the planned dose, where differences between the imaging scenarios become apparent. We selected this patient example because several issues can be observed here: Firstly, the dose distribution from imaging only differs strongly from the original treatment plan. Secondly, the dose distributions of the different imaging scenarios are quite different from each other, both in absolute dose (all imaging dose distributions are scaled to their respective maximum dose, ranging from 11.1 cGy for daily $\mathrm{kV}$ CBCT to 240.9 cGy in total for daily $6 \mathrm{MV} \mathrm{CBCT)} \mathrm{and} \mathrm{in} \mathrm{dose} \mathrm{distribution.} \mathrm{For} \mathrm{this} \mathrm{pa-}$ tient (patient 6), two target volumes were irradiated (lymphatics and os ileum), so that two series of imaging scenarios were simulated. The overlapping region between both imaging sets creates a higher-dose "belt" in the simulated scenarios. In the actual verification, most sessions only imaged the larger cranial planning target volume (PTV), so that most imaging dose is accumulated here. Furthermore, the actual verification used a combination of axial and CBCT imaging, which explains the square shape of the isodoses in this scenario.

If the combined dose from the radiotherapy treatment and imaging is considered, the differences between the scenarios are less obvious. Some small increases in the lower-dose isolines and an increased maximum dose are observed, particularly for those imaging scenarios with higher additional dose (e.g., $6 \mathrm{MV}$ ). For this patient, the actual imaging performed contributed rather high dose because this patient was treated among the first in the collective, when $\mathrm{kV}$ imaging was not yet installed at our department.

\section{Dose to organs at risk - DVH analysis}

An example DVH for the patient shown above is given in Fig. 3. It is obvious that the dose is markedly increased by daily $360^{\circ} 6 \mathrm{MV} \mathrm{CBCT}$, as well as (to a smaller degree) by the actual mixed CBCT-planar $6 \mathrm{MV}$ imaging performed. The other imaging scenarios do not result in a visible increase in the DVH dose. The fact that neither dose to the parotids nor the pharynx appear to change with the imaging scenarios is due to the imaging geometry visible in Fig. 2, in which the imaging beam does not reach up as far cranially to involve these organs.

All DVH parameters are listed in Table 3; an example for the left lung is displayed in Fig. 4. The statistical tests for significance using Wilcoxon's signed-rank test for paired data gave positive results for all organs for which more than 5 patient cases with DVH values existed, because the comparison of any plan with imaging vs. the original plan without imaging always gave positive ranks. Only for those DVH measures such as the D20Gy for the parotid could significance not be reached because of the variability of the plans, which meant that more than half of the patients had D20Gy $=0 \%$ for this organ.

As the target volumes and hence treatment plans vary considerably between the patients, the DVH parameters are also very different. Figure 4 shows the variation in DVH parameters for the left lung for the whole patient collective only for the original treatment plan without imaging. The additional dose from imaging creates less absolute difference than the variation between the individual patients, as can be seen for the example of the left lung values in Figs. 5 and 6. For the parotid mean and $\mathrm{D} 2 \%$ values, even the extreme imaging scenario with daily 6 MV CBCT only increases dose by less than $1 \mathrm{~Gy}$. For the spinal cord, the D2\% dose increases from 19.7 Gy without imaging to at most 21.2 Gy (daily 6 $\mathrm{MV}$ ), and by only 0.1 Gy for scenarios with $\mathrm{kV}$ imaging. Similar results are obtained for the pharynx and maximum (D2\%) and mean lung doses. For the lower-dose DVH values, the differences increase somewhat, e.g. by more than 5\% for the lung V20Gy and V5Gy. If the individual patient values (range) are considered rather than the average over the patient collective, strong variations appear, with V20\% for the lung ranging from $0 \%$ to over $46 \%$ and V5Gy from 56 to $100 \%$ within the collective.

\section{Imaging effect on secondary cancer risk}

Secondary cancer risk reflects the behavior of DVH values in varying more between individual patients than between imaging scenarios (Fig. 6, Table 4). Considering the original plan only (no imaging), the absolute excess cancer risk from treatment for the lungs is of the order of 5-6 cases per $10^{4} \mathrm{PY}$ (range $1.3-10$ per $10^{4} \mathrm{PY}$ ) and for the breast ranges between 2.4 and 26 per $10^{4} \mathrm{PY}$.

To concentrate on the effect of imaging rather than the inter-individual differences in target volume, we consider the differences between the original plan and the plans including imaging. The absolute excess risk from imaging only (disregarding the "baseline risk" from radiotherapy treatment) is given in Table 5 and shown in Fig. 7 for the left lung. Comparing this with Fig. 6 shows that the variability between the patients is drastically decreased, so that the systematic effect from imaging becomes visible. We can therefore now calculate the average additional risk over the patient collective (Fig. 8), which is considered in the following.

As was expected, daily 6 MV CBCT causes most additional cancer risk (more than 3 cases per $10^{4} \mathrm{PY}$ for the female breast and $0.7-0.8$ cases per $10^{4}$ PY for the lungs). If only $6 \mathrm{MV}$ imaging is available, the secondary cancer risk can be drastically decreased by preferentially performing planar images; in the case of daily planar 6 

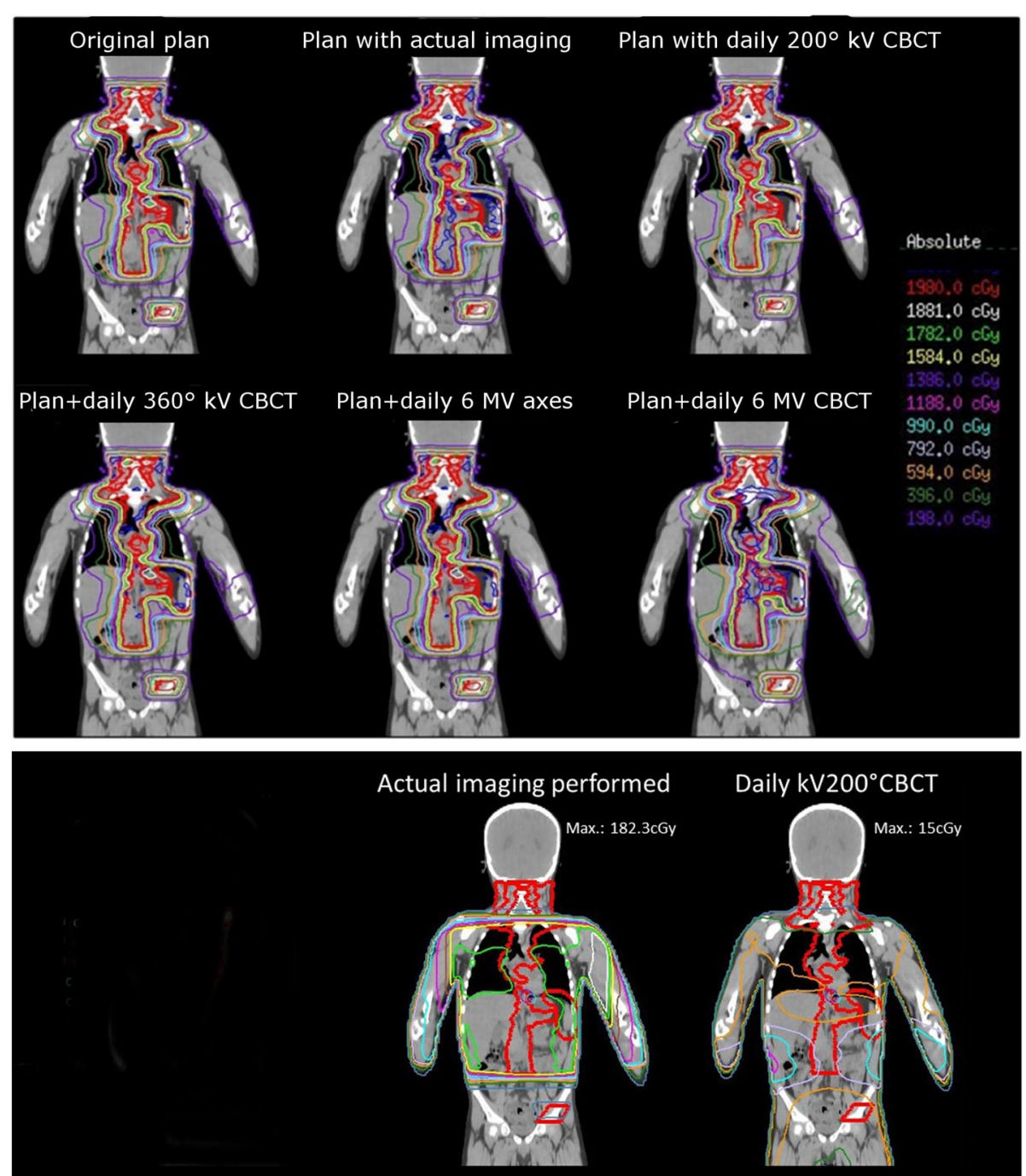

Daily kV360 $\mathrm{CBCT}$

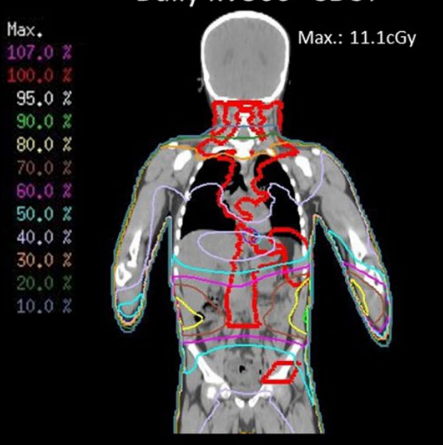

Daily TBL planar images

Daily TBL CBCT
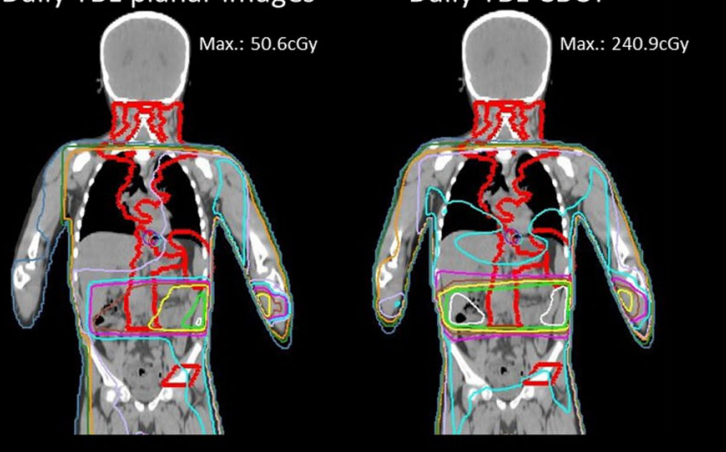

Fig. 2 Upper panel: dose distribution for the original treatment plan and summation plan including different imaging scenarios. Lower panel: dose distribution for different imaging scenarios only

MV imaging the additional excess absolute cancer risk for the breast is decreased to $0.4-0.8$ cases per $10^{4} \mathrm{PY}$ (a factor of 3.9-5.8) and to 0.1 cases for the lungs (more than a factor of 5). Slightly lower values are achieved by daily $360^{\circ} \mathrm{kV}$ CBCT $\left(0.44-0.57\right.$ per $10^{4} \mathrm{PY}$ for the breast and 0.08 per $10^{4} \mathrm{PY}$ for the lungs), which is again reduced for daily $200^{\circ} \mathrm{kV} \mathrm{CBCT}$. For this scenario, the additional excess absolute cancer risk for the lungs is 0.02 per $10^{4} \mathrm{PY}$ 


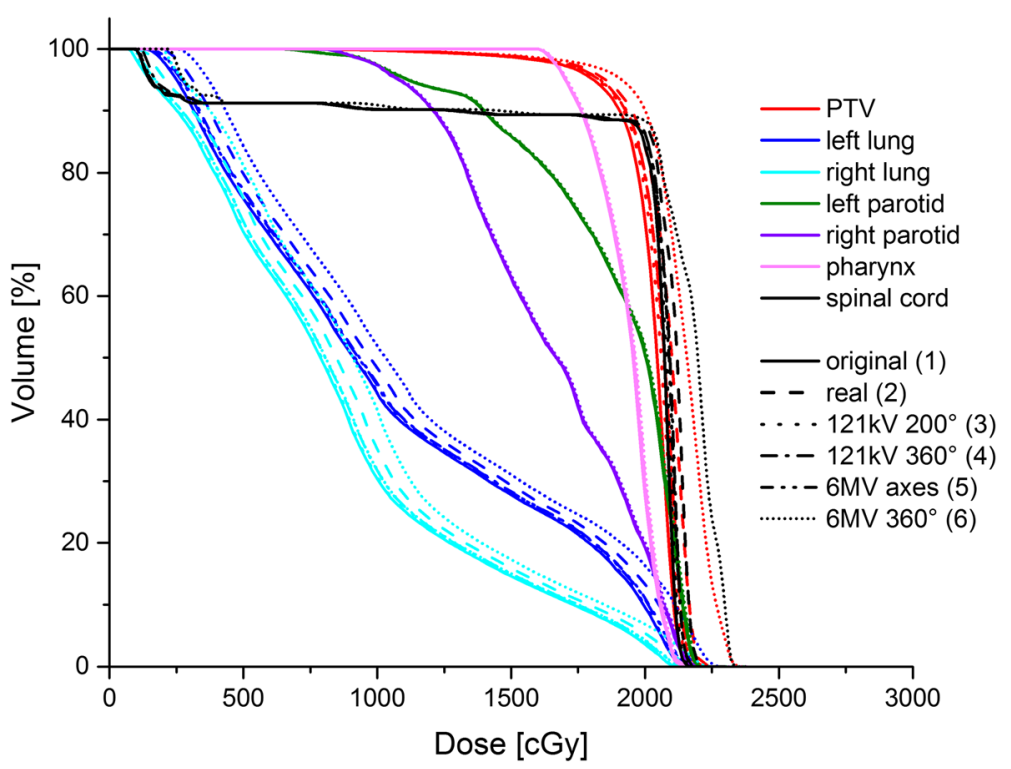

Fig. 3 Example DVH for original plan and different imaging scenarios (same patient as in Fig. 2)

(lower than $360^{\circ}$ by a factor of 4 ) and $0.07-0.08$ per $10^{4}$ PY for the breast (decreased by a factor of 6-7 with respect to the $360^{\circ} \mathrm{kV} \mathrm{CBCT} \mathrm{scenario).} \mathrm{The} \mathrm{reason} \mathrm{for} \mathrm{this}$ more pronounced improvement in the secondary cancer risk for the breast as compared with the lung is the geometry of the imaging system: The $200^{\circ} \mathrm{kV} \mathrm{CBCT}$ is taken rotating the X-ray source under the back of the patient, so that the breast only receives the much attenuated exit dose. As the lungs are located more centrally, the difference between a full CBCT rotation and a partial one does not produce such a pronounced effect. On average, the real imaging performed contributed about as much to secondary cancer risk as daily $\mathrm{kV} \mathrm{CBCT}$ with mixed $200^{\circ}$ and $360^{\circ} \mathrm{kV} \mathrm{CBCT}$ would have.

\section{Discussion}

We have mathematically estimated the risk for developing secondary cancers of the lung and female breast for a collective of eight pediatric patients (11 radiotherapy treatment plans) with Morbus Hodgkin based on the dose distribution from the treatment plan and several clinically relevant IGRT scenarios. Although there is relatively large variability between the patients, the additional risk from imaging could be determined. Depending on the imaging scenario used, the excess average risk at age 50 for developing a secondary cancer of the lungs ranged between 1.3 and 10 cases per $10^{4} \mathrm{PY}\left(0-2.3\right.$ per $10^{4} \mathrm{PY}$ only from imaging) and 2.4-27.5 cases per $10^{4} \mathrm{PY}\left(0.1-4.8\right.$ per $10^{4} \mathrm{PY}$ from imaging) for a secondary cancer of the female breast.

\section{Influence of assumed age at secondary cancer incidence} Our estimates for the EAR of secondary cancer development depend on the age attained included in the model.
We have opted for a relatively young age of 50 years, since this is already more than 30 years after treatment (age of exposure was set to the real age of the patients at treatment) and since this would be an age at which all possible therapeutic measures would most probably still be taken to cure the secondary malignancy.

The value assumed for the age attained only influences the risk estimate via the modifying function $\mu$, which directly scales with the EAR. For our patient collective and an assumed age attained of 50 years, $\mu$ for the lungs is of the order of 0.23 , but strongly increases with age attained to $0.95-0.97$ for 70 years and about 2.8 for 90 years. This explains to some degree the relatively small EAR values obtained in our study. By considering an attained age of 70 rather than 50 years, all presented risk values would be increased about fourfold, and up to a factor 12 if a long life expectancy as 90 years is assumed. For breast cancer, $\mu$ varies more between the patients, as the dependence on the age at exposure is stronger. For an attained age of 50 years, $\mu$ is between 0.95 and 1.32 , increasing to $1.7-2.3$ for an attained age of 70 years and to 2.5-3.6 for 90 years. Here, the age attained only increases the estimated EAR by a factor of less than 3.

\section{Influence of modelling approach}

All models for secondary cancer induction are simplified estimates based on the available evidence, which is complicated by the long latency periods and the existence of a large number of confounding factors influencing the risk of secondary cancer induction (e.g., additional chemotherapy, life-style and other exposures such as smoking, etc.). While a numbers of models are available 
Table 3 Dose metrics for the organs at risk in the imaging scenarios (mean \pm standard deviation, range)

\begin{tabular}{|c|c|c|c|c|c|c|c|}
\hline Organ & Criteria & Scenario1 & Scenario 2 & Scenario 3 & Scenario 4 & Scenario 5 & Scenario 6 \\
\hline \multirow[t]{5}{*}{ Lung le } & D mean [Gy] & $\begin{array}{l}9.13 \pm 4.88 \\
(2.62-17.43)\end{array}$ & $\begin{array}{l}9.27 \pm 4.90 \\
(2.74-17.54)\end{array}$ & $\begin{array}{l}9.17 \pm 4.90 \\
(2.65-17.53)\end{array}$ & $\begin{array}{l}9.28 \pm 4.96 \\
(2.74-17.80)\end{array}$ & $\begin{array}{l}9.39 \pm 5.01 \\
(2.81-17.98)\end{array}$ & $\begin{array}{l}10.46 \pm 5.62 \\
(3.59-20.25)\end{array}$ \\
\hline & V20Gy [\%] & $\begin{array}{l}9.72 \pm 12.07 \\
(0.00-32.26)\end{array}$ & $\begin{array}{l}11.04 \pm 12.55 \\
(0.00-32.55)\end{array}$ & $\begin{array}{l}9.91 \pm 12.20 \\
(0.00-32.54)\end{array}$ & $\begin{array}{l}10.33 \pm 12.52 \\
(0.00-33.34)\end{array}$ & $\begin{array}{l}10.73 \pm 12.74 \\
(0.00-33.84)\end{array}$ & $\begin{array}{l}14.63 \pm 15.05 \\
(0.00-40.55)\end{array}$ \\
\hline & V10Gy [\%] & $\begin{array}{l}39.27 \pm 27.78 \\
(2.33-88.37)\end{array}$ & $\begin{array}{l}40.03 \pm 27.99 \\
(2.44-88.88)\end{array}$ & $\begin{array}{l}39.46 \pm 27.92 \\
(2.35-88.85)\end{array}$ & $\begin{array}{l}39.89 \pm 28.27 \\
(2.43-90.16)\end{array}$ & $\begin{array}{l}40.36 \pm 28.54 \\
(2.49-91.08)\end{array}$ & $\begin{array}{l}44.55 \pm 30.80 \\
(3.20-98.92)\end{array}$ \\
\hline & V5Gy [\%] & $\begin{array}{l}59.29 \pm 29.06 \\
(11.03-100)\end{array}$ & $\begin{array}{l}60.2 \pm 29.24 \\
(11.92-100)\end{array}$ & $\begin{array}{l}59.46 \pm 29.06 \\
(11.23-100)\end{array}$ & $\begin{array}{l}59.9 \pm 28.97 \\
(11.92-100)\end{array}$ & $\begin{array}{l}60.38 \pm 29.01 \\
(12.38-100)\end{array}$ & $\begin{array}{l}67.28 \pm 30.31 \\
(20.45-100)\end{array}$ \\
\hline & D 2\% [Gy] & $\begin{array}{l}20.81 \pm 6.98 \\
(3.33-31.78)\end{array}$ & $\begin{array}{l}20.96 \pm 6.96 \\
(3.43-31.84)\end{array}$ & $\begin{array}{l}20.85 \pm 6.99 \\
(3.37-31.84)\end{array}$ & $\begin{array}{l}20.98 \pm 7.03 \\
(3.45-32.05)\end{array}$ & $\begin{array}{l}21.14 \pm 7.07 \\
(3.47-32.11)\end{array}$ & $\begin{array}{l}22.12 \pm 7.39 \\
(4.33-34.14)\end{array}$ \\
\hline \multirow[t]{5}{*}{ Lung ri } & D mean [Gy] & $\begin{array}{l}9.2 \pm 6.10 \\
(1.58-18.66)\end{array}$ & $\begin{array}{l}9.33 \pm 6.12 \\
(1.65-18.72)\end{array}$ & $\begin{array}{l}9.24 \pm 6.12 \\
(1.61-18.74)\end{array}$ & $\begin{array}{l}9.29 \pm 6.08 \\
(1.68-18.60)\end{array}$ & $\begin{array}{l}9.38 \pm 6.18 \\
(1.65-18.99)\end{array}$ & $\begin{array}{l}10.43 \pm 6.62 \\
(2.26-20.98)\end{array}$ \\
\hline & V20Gy [\%] & $\begin{array}{l}10.1 \pm 13.08 \\
(0.00-38.70)\end{array}$ & $\begin{array}{l}10.6 \pm 13.14 \\
(0.00-38.89)\end{array}$ & $\begin{array}{l}10.2 \pm 13.68 \\
(0.00-38.92)\end{array}$ & $\begin{array}{l}10.62 \pm 13.44 \\
(0.00-39.56)\end{array}$ & $\begin{array}{l}10.9 \pm 13.52 \\
(0.00-39.67)\end{array}$ & $\begin{array}{l}15.32 \pm 16.26 \\
(0.00-46.67)\end{array}$ \\
\hline & V10Gy [\%] & $\begin{array}{l}41.13 \pm 35.44 \\
(0.00-98.93)\end{array}$ & $\begin{array}{l}41.86 \pm 35.30 \\
(0.00-98.94)\end{array}$ & $\begin{array}{l}41.26 \pm 35.47 \\
(0.00-98.93)\end{array}$ & $\begin{array}{l}41.52 \pm 35.55 \\
(0.00-98.95)\end{array}$ & $\begin{array}{l}41.70 \pm 35.51 \\
(0.00-98.96)\end{array}$ & $\begin{array}{l}45.4 \pm 36.36 \\
(0.00-99.12)\end{array}$ \\
\hline & V5Gy [\%] & $\begin{array}{l}56.29 \pm 35.96 \\
(0.00-100)\end{array}$ & $\begin{array}{l}57.13 \pm 36.30 \\
(0.00-100)\end{array}$ & $\begin{array}{l}56.45 \pm 35.96 \\
(0.00-100)\end{array}$ & $\begin{array}{l}56.8 \pm 35.90 \\
(0.00-100)\end{array}$ & $\begin{array}{l}57.03 \pm 35.95 \\
(0.00-100)\end{array}$ & $\begin{array}{l}62.4 \pm 36.23 \\
(0.00-100)\end{array}$ \\
\hline & D 2\% [Gy] & $\begin{array}{l}20.5 \pm 8.66 \\
(3.33-31.78)\end{array}$ & $\begin{array}{l}20.64 \pm 8.65 \\
(3.43-31.84)\end{array}$ & $\begin{array}{l}20.54 \pm 8.67 \\
(3.37-31.48)\end{array}$ & $\begin{array}{l}20.65 \pm 8.70 \\
(3.45-32.05)\end{array}$ & $\begin{array}{l}20.72 \pm 8.73 \\
(3.47-32.11)\end{array}$ & $\begin{array}{l}21.72 \pm 9.24 \\
(4.33-34.14)\end{array}$ \\
\hline \multirow[t]{2}{*}{ Breast le } & D mean [Gy] & $\begin{array}{l}3.10 \pm 2.84 \\
(0.74-7.06)\end{array}$ & $\begin{array}{l}3.19 \pm 2.81 \\
(0.87-7.10)\end{array}$ & $\begin{array}{l}3.13 \pm 2.86 \\
(0.76-7.11)\end{array}$ & $\begin{array}{l}3.29 \pm 2.95 \\
(0.89-7.44)\end{array}$ & $\begin{array}{l}3.38 \pm 3.01 \\
(0.94-7.62)\end{array}$ & $\begin{array}{l}4.27 \pm 3.53 \\
(1.60-9.34)\end{array}$ \\
\hline & D 2\% [Gy] & $\begin{array}{l}12.60 \pm 5.65 \\
(8.85-20.89)\end{array}$ & $\begin{array}{l}12.67 \pm 5.53 \\
(9.01-20.75)\end{array}$ & $\begin{array}{l}12.56 \pm 5.59 \\
(8.86-20.75)\end{array}$ & $\begin{array}{l}12.76 \pm 5.66 \\
(9.02-21.05)\end{array}$ & $\begin{array}{l}12.86 \pm 5.70 \\
(9.08-21.21)\end{array}$ & $\begin{array}{l}13.93 \pm 6.12 \\
(9.90-22.89)\end{array}$ \\
\hline \multirow[t]{2}{*}{ Breast ri } & D mean [Gy] & $\begin{array}{l}5.81 \pm 4.80 \\
(1.37-11.53)\end{array}$ & $\begin{array}{l}5.89 \pm 4.82 \\
(1.41-11.67)\end{array}$ & $\begin{array}{l}5.83 \pm 4.81 \\
(1.38-11.56)\end{array}$ & $\begin{array}{l}6.0 \pm 4.85 \\
(1.49-11.73)\end{array}$ & $\begin{array}{l}6.01 \pm 4.86 \\
(1.50-11.75)\end{array}$ & $\begin{array}{l}6.97 \pm 5.13 \\
(2.16-12.82)\end{array}$ \\
\hline & D 2\% [Gy] & $\begin{array}{l}16.08 \pm 6.12 \\
(9.84-21.41)\end{array}$ & $\begin{array}{l}16.18 \pm 6.12 \\
(9.90-21.43)\end{array}$ & $\begin{array}{l}16.09 \pm 6.12 \\
(9.85-21.43)\end{array}$ & $\begin{array}{l}16.28 \pm 6.17 \\
(9.99-21.43)\end{array}$ & $\begin{array}{l}16.34 \pm 6.19 \\
(10.03-21.70)\end{array}$ & $\begin{array}{l}17.41 \pm 6.46 \\
(10.83-23.31)\end{array}$ \\
\hline \multirow[t]{2}{*}{ Parotid le } & D mean [Gy] & $\begin{array}{l}5.25 \pm 7.94 \\
(0.17-18.71)\end{array}$ & $\begin{array}{l}5.29 \pm 7.92 \\
(0.20-18.75)\end{array}$ & $\begin{array}{l}5.28 \pm 7.93 \\
(0.20-18.71)\end{array}$ & $\begin{array}{l}5.36 \pm 7.91 \\
(0.27-18.72)\end{array}$ & $\begin{array}{l}5.38 \pm 7.92 \\
(0.21-18.72)\end{array}$ & $\begin{array}{l}5.98 \pm 7.82 \\
(0.55-18.78)\end{array}$ \\
\hline & D 2\% [Gy] & $\begin{array}{l}6.68 \pm 9.76 \\
(0.24-21.78)\end{array}$ & $\begin{array}{l}6.74 \pm 9.53 \\
(0.36-21.82)\end{array}$ & $\begin{array}{l}6.71 \pm 9.75 \\
(0.28-21.78)\end{array}$ & $\begin{array}{l}6.66 \pm 9.70 \\
(0.40-21.78)\end{array}$ & $\begin{array}{l}6.86 \pm 9.71 \\
(0.41-21.79)\end{array}$ & $\begin{array}{l}7.62 \pm 9.52 \\
(1.20-21.86)\end{array}$ \\
\hline \multirow[t]{4}{*}{ Parotid ri } & D mean [Gy] & $\begin{array}{l}3.77 \pm 5.96 \\
(0.39-16.50)\end{array}$ & $\begin{array}{l}3.81 \pm 5.95 \\
(0.43-16.53)\end{array}$ & $\begin{array}{l}3.80 \pm 5.95 \\
(0.42-16.50)\end{array}$ & $\begin{array}{l}3.89 \pm 5.92 \\
(0.50-16.51)\end{array}$ & $\begin{array}{l}3.90 \pm 5.92 \\
(0.45-16.51)\end{array}$ & $\begin{array}{l}4.51 \pm 5.74 \\
(0.77-16.57)\end{array}$ \\
\hline & D 2\% [Gy] & $\begin{array}{l}5.50 \pm 7.92 \\
(0.62-21.41)\end{array}$ & $\begin{array}{l}5.48 \pm 7.92 \\
(0.73-21.46)\end{array}$ & $\begin{array}{l}5.48 \pm 7.91 \\
(0.66-21.42)\end{array}$ & $\begin{array}{l}5.58 \pm 7.88 \\
(0.78-21.43)\end{array}$ & $\begin{array}{l}5.59 \pm 7.87 \\
(0.79-21.43)\end{array}$ & $\begin{array}{l}6.37 \pm 7.60 \\
(1.59-21.49)\end{array}$ \\
\hline & OED & $\begin{array}{l}0.79 \pm 0.82 \\
(0.14-2.20)\end{array}$ & $\begin{array}{l}0.81 \pm 0.81 \\
(0.20-2.20)\end{array}$ & $\begin{array}{l}0.81 \pm 0.82 \\
(0.16-2.20)\end{array}$ & $\begin{array}{l}0.84 \pm 0.80 \\
(0.22-2.20)\end{array}$ & $\begin{array}{l}0.84 \pm 0.80 \\
(0.22-2.20)\end{array}$ & $\begin{array}{l}1.05 \pm 0.70 \\
(0.36-2.20)\end{array}$ \\
\hline & EAR & $\begin{array}{l}0.43 \pm 0.47 \\
(0.08-1.31)\end{array}$ & $\begin{array}{l}0.43 \pm 0.47 \\
(0.09-1.31)\end{array}$ & $\begin{array}{l}0.43 \pm 0.47 \\
(0.09-1.28)\end{array}$ & $\begin{array}{l}0.45 \pm 0.46 \\
(0.11-1.31)\end{array}$ & $\begin{array}{l}0.45 \pm 0.46 \\
(0.10-1.31)\end{array}$ & $\begin{array}{l}0.55 \pm 0.42 \\
(0.16-1.31)\end{array}$ \\
\hline \multirow[t]{2}{*}{ Pharynx } & D mean [Gy] & $\begin{array}{l}6.51 \pm 7.52 \\
(0.72-19.34)\end{array}$ & $\begin{array}{l}6.56 \pm 7.50 \\
(0.84-19.38)\end{array}$ & $\begin{array}{l}6.53 \pm 7.49 \\
(0.75-19.34)\end{array}$ & $\begin{array}{l}6.62 \pm 7.49 \\
(0.87-19.35)\end{array}$ & $\begin{array}{l}6.66 \pm 7.48 \\
(0.93-19.36)\end{array}$ & $\begin{array}{l}7.38 \pm 7.28 \\
(2.05-19.43)\end{array}$ \\
\hline & D 2\% [Gy] & $\begin{array}{r}12.28 \pm 7.29 \\
(1.06-21.05)\end{array}$ & $\begin{array}{l}12.37 \pm 7.24 \\
(1.18-21.11)\end{array}$ & $\begin{array}{l}12.31 \pm 7.28 \\
(1.09-21.06)\end{array}$ & $\begin{array}{l}12.48 \pm 7.25 \\
(1.22-21.06)\end{array}$ & $\begin{array}{l}12.39 \pm 7.19 \\
(1.27-21.07)\end{array}$ & $\begin{array}{l}13.33 \pm 6.95 \\
(2.41-21.15)\end{array}$ \\
\hline Spinal cord & D 2\% [Gy] & $\begin{array}{l}19.66 \pm 7.97 \\
(6.36-29.53)\end{array}$ & $\begin{array}{l}19.8 \pm 7.97 \\
(6.46-29.60)\end{array}$ & $\begin{array}{l}19.71 \pm 7.99 \\
(6.40-29.61)\end{array}$ & $\begin{array}{l}19.81 \pm 8.02 \\
(6.48-29.80)\end{array}$ & $\begin{array}{l}19.89 \pm 8.05 \\
(6.50-29.90)\end{array}$ & $\begin{array}{l}21.17 \pm 8.43 \\
(7.41-31.67)\end{array}$ \\
\hline
\end{tabular}

with parametrizations for different OAR's, it is as yet unclear which class of model (linear-non-threshold, plateau or bell-shaped) should be considered the most realistic. The full model by Schneider et al. [12] has the intuitive plausibility that high doses leading to cell kill would not be expected to be as cancerogenetic as lower doses resulting only in DNA damage without cell death. However, this hypothesis is not unanimously adopted, as some studies have also supported a linear relationship (compare Filippi et al. for a recent review [13]).

If the assumption of a bell-shaped model should hold true, however, it is highly relevant that all dose contributions 


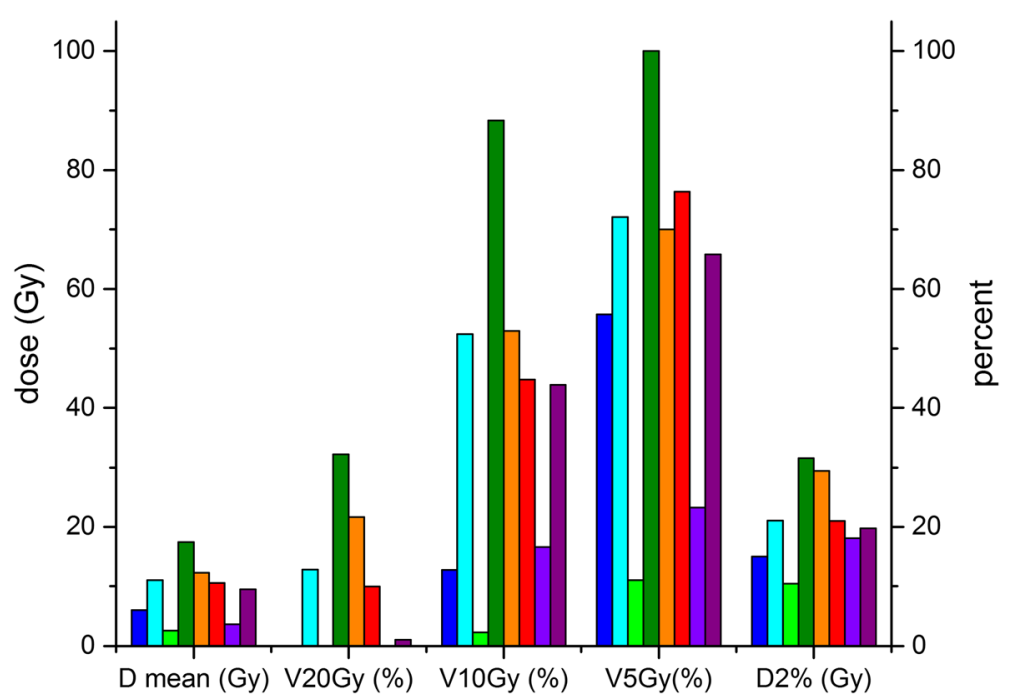

Fig. 4 Dose metrics for the left lung (all patients). Shown are 8 separate data sets because one patient received two separate planning CTs for the two target sites

should be summed together for secondary cancer estimation, rather than considering the effects individually. If the secondary cancer risk from imaging and from treatment were assessed separately from one another, the linear model would be applied to the small doses implicated from imaging. In principle, this approach would be invalid if the treatment dose is far from the linear dose-risk regime, so that the contributions from imaging and treatment are not additive in the simple sense. However, in some cases there is no way of performing a combined imaging plus treatment dose assessment for secondary cancer risk, e.g. if no information on the treatment dose exists and just general conclusions about different imaging systems and their comparison with each other are drawn [14].

While emphasizing that this approach should be avoided because of the presumed non-linear shape of the dose-risk

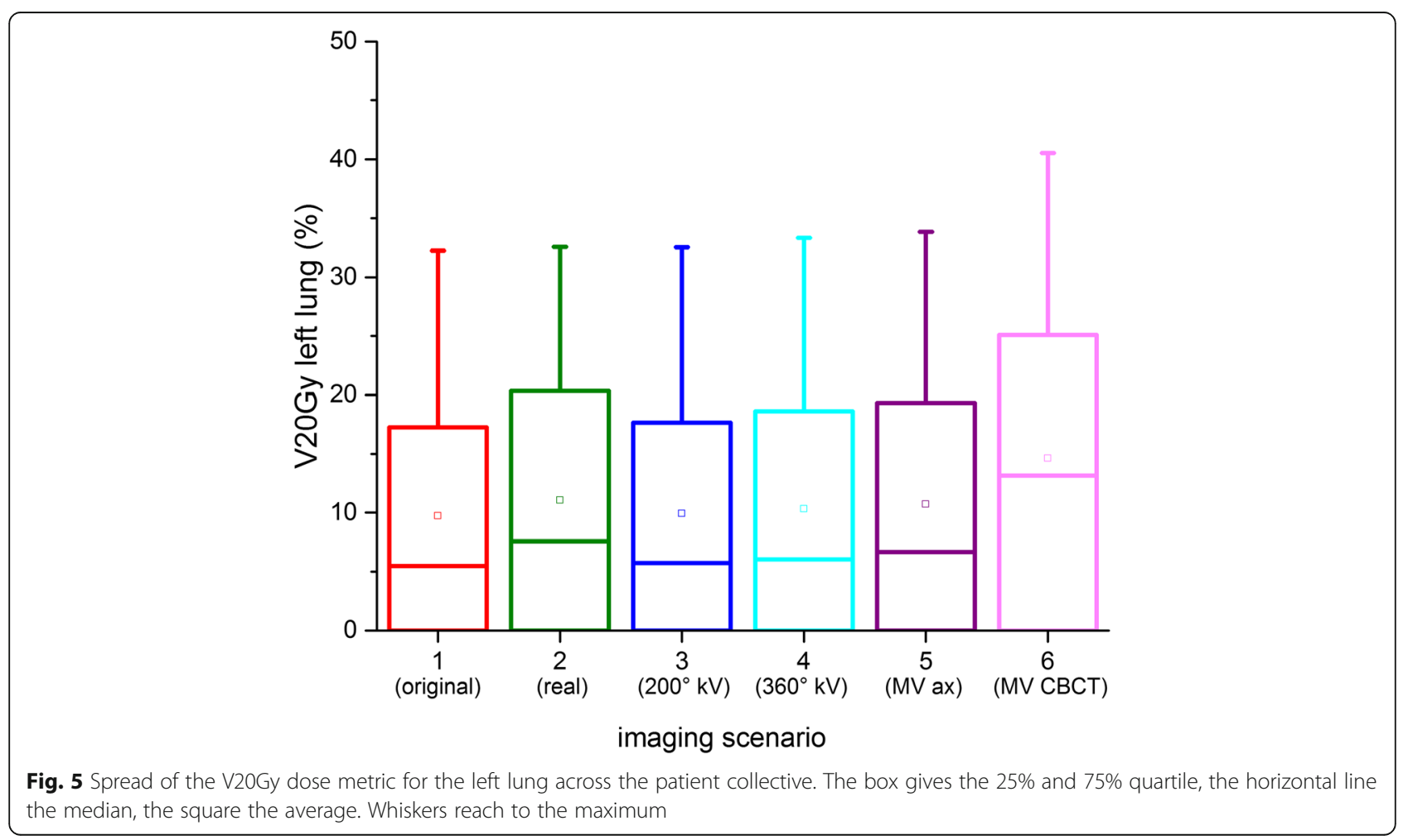




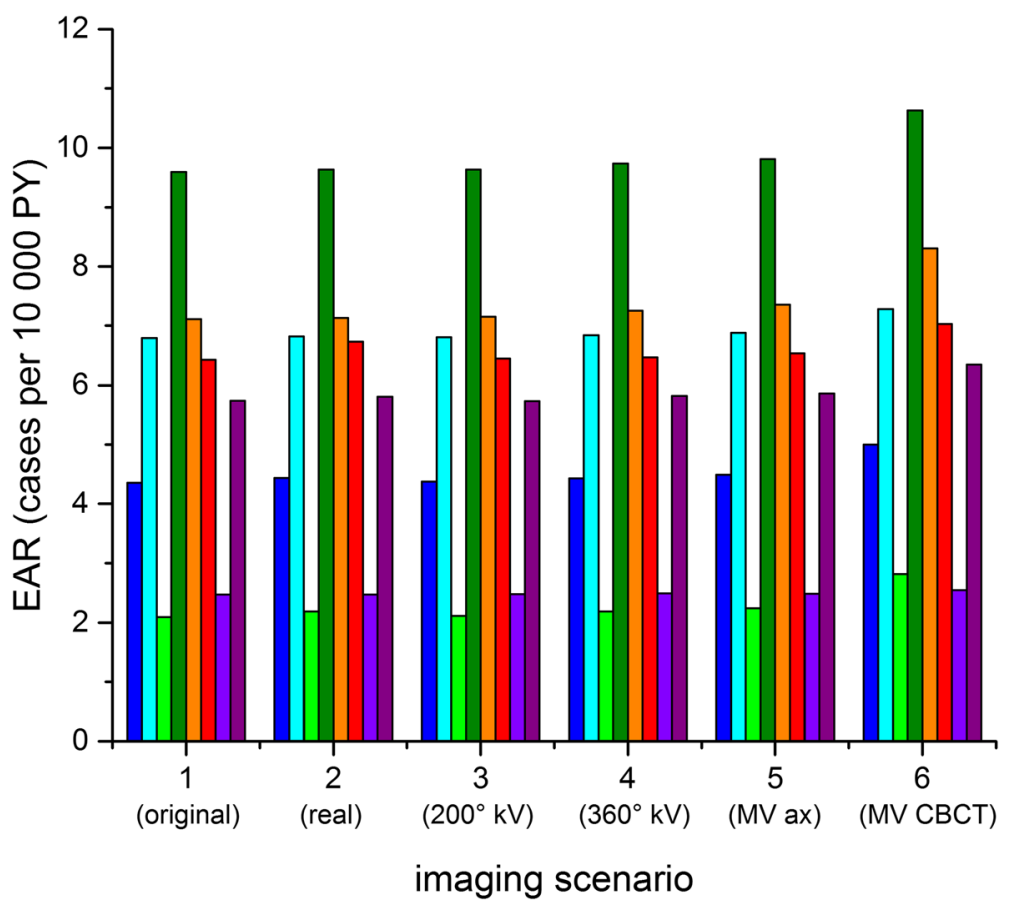

Fig. 6 Excess absolute cancer risk for the left lung for the patient collective modelled for different imaging scenarios (each colour bar corresponds to an individual patient $C T$ data set)

curve, we perform this estimation to demonstrate in how far the results would be influenced by following this approach, as it is sometimes adopted in the literature. Table 6 gives the average dose to the lung and breast from imaging only for the different scenarios, and the resulting secondary cancer risk from the linear model $(\operatorname{RED}(D)=\mathrm{D})$. The estimated risk from this method is considerably higher (by a factor 3-4) than the risk resulting from the clinically realistic scenario in

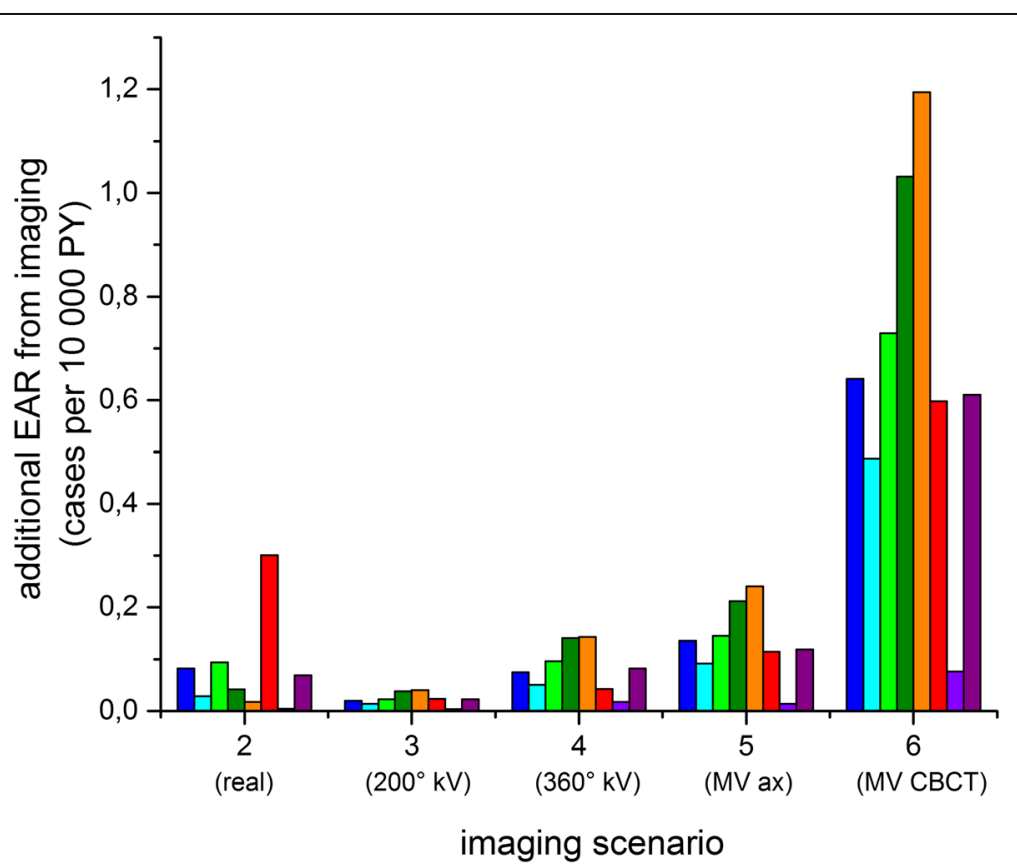

Fig. 7 Additional EAR from imaging only (difference between total EAR as shown in Fig. 6 and EAR from the original plan, each colour bar corresponds to an individual patient CT data set) 
Table 4 Excess absolute risk (in cases per $10^{4}$ PY): average \pm standard deviation (min-max)

\begin{tabular}{lllllll}
\hline & $\begin{array}{l}\text { Scenario 1 } \\
\text { (original) }\end{array}$ & $\begin{array}{l}\text { Scenario 2 } \\
\text { (real) }\end{array}$ & $\begin{array}{l}\text { Scenario 3 } \\
\left(200^{\circ} \mathrm{kV}-\mathrm{CBCT}\right)\end{array}$ & $\begin{array}{l}\text { Scenario 4 } \\
\left(360^{\circ} \mathrm{kV}-\mathrm{CBCT}\right)\end{array}$ & $\begin{array}{l}\text { Scenario 5 } \\
(6 \mathrm{MV} \text { axes) }\end{array}$ & $\begin{array}{l}\text { Scenario 6 } \\
(6 \mathrm{MV} \text { CBCT) }\end{array}$ \\
\hline Left lung & $5.58 \pm 2.5(2.1-9.6)$ & $5.66 \pm 2.5(2.2-9.6)$ & $6.25 \pm 2.7(2.6-10.6)$ & $5.72 \pm 2.6(2.2-9.9)$ & $5.65 \pm 2.5(2.2-9.7)$ & $5.60 \pm 2.5(2.1-9.6)$ \\
Right lung & $5.54 \pm 3.2(1.3-10.0)$ & $5.62 \pm 3.2(1.4-10.0)$ & $6.17 \pm 3.3(1.9-10.8)$ & $5.64 \pm 3.2(1.4-10.1)$ & $5.62 \pm 3.2(1.4-10.1)$ & $5.56 \pm 3.2(1.3-10.0)$ \\
Left breast & $8.73 \pm 6.9(2.4-17.9)$ & $9.03 \pm 6.8(2.8-18.0)$ & $11.87 \pm 7.7(5.3-22.7)$ & $9.53 \pm 7.1(3.0-19.2)$ & $9.30 \pm 7.0(2.9-18.8)$ & $8.81 \pm 6.9(2.4-18.0)$ \\
Right breast & $14.12 \pm 10.3(4.8-26.0)$ & $14.29 \pm 10.2(5.0-26.2)$ & $16.63 \pm 10.0(7.7-27.5)$ & $14.56 \pm 10.2(5.3-26.3)$ & $14.57 \pm 10.2(5.3-26.3)$ & $14.19 \pm 10.2(4.9-26.1)$ \\
\hline
\end{tabular}

which imaging dose and treatment dose act together simultaneously. The possible non-linearity in the risk curve thus plays a significant role and different coinciding contributions to dose should be analysed together, if this is possible.

\section{Comparison with previous studies}

A number of studies have estimated imaging dose for MV and $\mathrm{kV}$ modalities in either planar or CBCT geometries, although relatively few have considered pediatric patients. For the Varian On-Board Imager (OBI) system (Varian Medical Systems, Palo Alto, California, USA), Ding et al. [15] obtained doses to soft tissue of the order of 4-10 cGy (half-fan) and 3-9 cGy (full-fan mode) for pediatric patients with imaging in the head-and-neck region using the Vanderbilt-Monte-Carlo-Beam-Calibration algorithm. Similar dose values (1.9-10.5 cGy depending on the organ) were reported by Deng et al. [16] for $125 \mathrm{kVp}$ voltage based on Monte Carlo methods. Measurements in an anthropomorphic phantom (adult and pediatric) [17] confirm this order of magnitude. Our calculated average organ doses for the $\mathrm{kV}$ imaging scenarios are larger than the original treatment plan dose by up to 20 cGy for daily imaging (up to 16 fractions, which means a few cGy per image). This is in good agreement with previous studies, which can be expected since dose calculations for our system also agreed well with those from Varian and Elekta (Elekta, Stockholm, Sweden) for other tumor indications.

Regarding secondary cancer risk estimates, the results from previous studies are rather varied depending on the assumed target localization, dose distribution and secondary cancer model (for reviews, see $[18,19]$ and references therein). Comparing our predictions with clinical data, Dörffel et al. [20] observed an absolute excess risk of developing secondary malignancies at the breast of 14.9 per 10,000 PY in a cohort study of 2548 patients treated for Hodgkin's Lymphoma within 30 years' follow-up, which agrees well with the range of values obtained in our study (2-26 cases per 10,000 PY). In their review, Kamran et al. [21] list an absolute risk for breast cancer after Hodgkin lymphoma of 37 per 10,000 PY; Schaapveld et al. [22] estimate an EAR of 20.5-29.3 per 10,000 PY for the lung and 44.7-65.0 per 10,000 PY for the breast. Since our prediction is for an attained age of 50 years and increases with higher age, the agreement is still plausible.

Only few studies have focused on secondary cancer risk from imaging in radiotherapy. Zhang et al. [23] presented imaging dose from Varian $\mathrm{kV} \mathrm{CBCT}$ as a function of patient chest circumference, where organ mean dose per scan was of the order of 0.8-3 cGy (in agreement with our results), but used the BEIR VII model to transfer these values into relative risks for secondary cancer. As we have pointed out, the non-linear behaviour of the cancer risk curve should be accounted for by considering the combination of treatment and imaging dose where this is possible. For this high-dose regime, it is more common to use Schneider's full mechanistic model; however, this is usually applied to treatment plans rather than IGRT scenarios [24]. To our knowledge, our study is the first one to include imaging scenarios in the radiotherapy treatment plan for an accurate assessment of additional cancer risk in the dose regime used for treatment.

\section{Limitations and implications of this study}

In addition to the relatively small patient collective available for our study, it must be born in mind that the treatment plans were not particularly optimized to minimize secondary cancer risk, neither for optimal

Table 5 Additional EAR from imaging only (in cases per $10^{4} \mathrm{PY}$, average \pm standard deviation, range in braces)

\begin{tabular}{llllll}
\hline Organ & Scenario 2 (real) & Scenario 3 $\left(200^{\circ} \mathrm{kV}-\mathrm{CBCT}\right)$ & Scenario 4 $\left(360^{\circ} \mathrm{kV}-\mathrm{CBCT}\right)$ & Scenario 5 $(6 \mathrm{MV}$ axes) & Scenario 6 (6MV CBCT) \\
\hline Left lung & $0.08 \pm 0.09$ & $0.02 \pm 0.01$ & $0.08 \pm 0.04$ & $0.13 \pm 0.07$ & $0.67 \pm 0.34$ \\
& $(0.00-0.30)$ & $(0.00-0.04)$ & $(0.02-0.14)$ & $(0.01-0.24)$ & $(0.08-1.19)$ \\
Right lung & $0.07 \pm 0.11$ & $0.02 \pm 0.01$ & $0.08 \pm 0.05$ & $0.1 \pm 0.06$ & $0.75 \pm 0.66$ \\
& $(0.00-0.07)$ & $(0.00-0.04)$ & $(0.02-0.16)$ & $(0.01-0.21)$ & $(0.08-2.31)$ \\
Left breast & $0.29 \pm 0.16$ & $0.08 \pm 0.03$ & $0.57 \pm 0.22$ & $0.8 \pm 0.33$ & $3.14 \pm 1.19$ \\
& $(0.11-0.46)$ & $(0.06-0.12)$ & $(0.38-0.88)$ & $(0.55-1.29)$ & $(1.99-4.81)$ \\
Right breast & $0.18 \pm 0.09$ & $0.07 \pm 0.02$ & $0.44 \pm 0.16$ & $0.43 \pm 0.13$ & $2.51 \pm 0.77$ \\
& $(0.09-0.31)$ & $(0.04-0.09)$ & $(0.25-0.64)$ & $(0.27-0.58)$ & $(1.50-3.33)$ \\
\hline
\end{tabular}




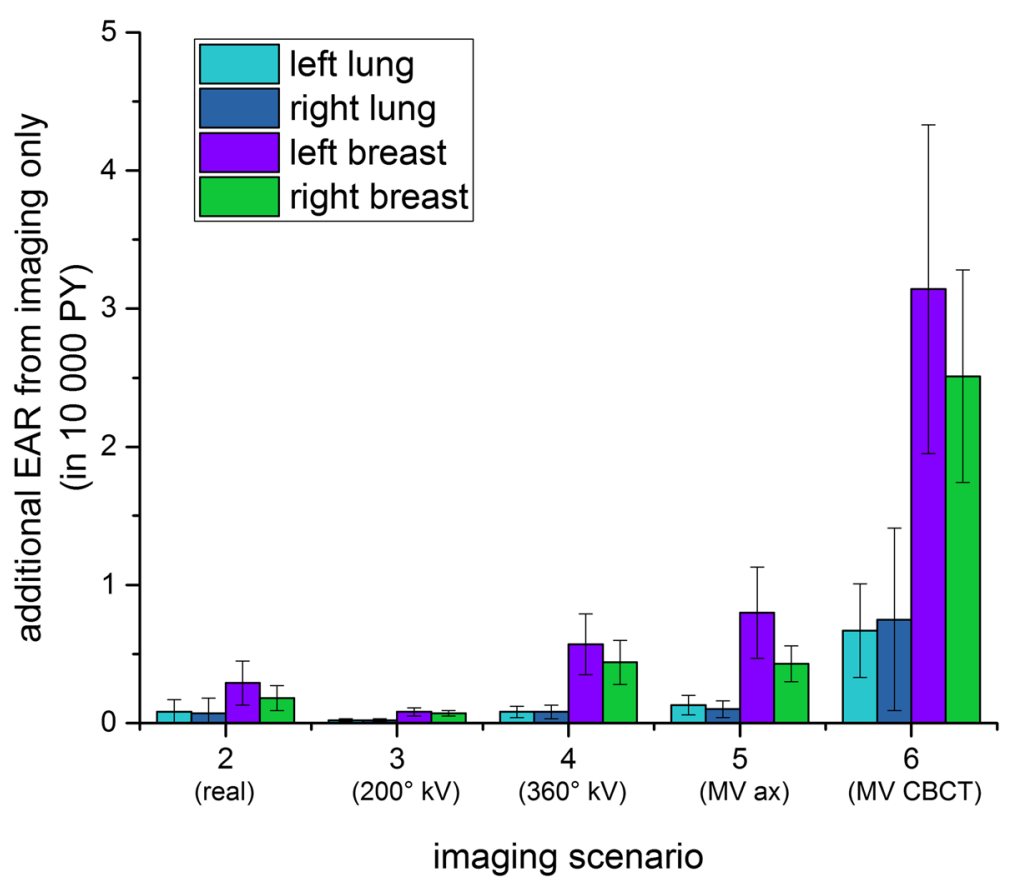

Fig. 8 Additional EAR from imaging only, average (with standard deviation) over all patients

sparing of the female breast. Although these organs are taken into account as an organs at risk in our planning process, a compromise was made for best sparing of all healthy organs, so that the two sites at most risk for secondary cancer incidence were not prioritized over the other OAR's. While all patients were treated with the involved field technique, the target volumes showed strong variation (PTV volumes $54-2419 \mathrm{~cm}^{3}$, average $1145 \mathrm{~cm}^{3}$ ). Most patients were treated using step-and-shoot IMRT (4-14 beams with between 30 and 70 segments), only very small target volumes (e.g., case 9, os ileum) were treated using 3D conformal radiotherapy (3D CRT with 2 beams). Volumetric modulated arc therapy (VMAT) plans were never used. The number of beams and segments used in the IMRT plans varied individually. In addition to setting objectives for the organs at risk, ring and normal tissue structures were created to form a dose gradient around the target volume.

Despite the large variability between the patients, the DVH metrics correspond to those reported by other authors. For example, Maraldo et al. [25] assessed normal tissue doses for different radiotherapy targets for patients with Hodgkin's lymphoma. For the lungs, they found mean doses in the range of $30-52 \%$ of the prescribed dose (30 Gy in their study, i.e. 11.7-15.6 Gy) for mantle field and mediastinal irradiation and 2.2-4.0 Gy for neck and axilla irradiation, which agrees with the range of doses from our collective (1.6-18.7 Gy mean lung dose). Similarly, their values for the female breast were between 1.4 and 17 Gy depending on the treatment fields, corresponding to our dose range between 0.7 and $11.5 \mathrm{~Gy}$.

Regarding margins for the PTV, in a previous unpublished study (similar to [8]) we analyzed positioning errors for a collective of children, resulting in a systematic population setup error of $0.7 / 1.0 /-0.2 \mathrm{~mm}$ in the anterior-posterior (AP)/left-right (LR) and superior-/inferior (SI) directions, a variation of population setup error of 1.7/2.6/2.5 mm (AP/ $\mathrm{LR} / \mathrm{SI}$ ) and a population random error or 3.9/4.9/3.9 mm (AP/LR/SI), which yields a CTV-PTV margin of 8.2/11.4/ $10.2 \mathrm{~mm}$ according to the margin recipe by van Herk et al.

Table 6 Additional EAR from imaging only if imaging was considered separately from the treatment plan

\begin{tabular}{llllll}
\hline & Scenario 2 (real) & Scenario $3\left(200^{\circ} \mathrm{kV}-\mathrm{CBCT}\right)$ & Scenario $4\left(360^{\circ} \mathrm{kV}\right.$-CBCT) & Scenario $5(6 \mathrm{MV}$ axes) & Scenario 6 (6MV CBCT) \\
\hline Left lung & $0.26 \pm 0.34(0-5.25)$ & $0.08 \pm 0.59(0-5.25)$ & $0.29 \pm 0.21(0.06-5.25)$ & $0.48 \pm 0.31(0.04-5.25)$ & $2.48 \pm 1.62(0.26-5.25)$ \\
Right lung & $0.25 \pm 0.34(0-1.07)$ & $0.07 \pm 0.48(0-0.15)$ & $0.18 \pm 0.17(0-0.48)$ & $0.34 \pm 0.21(0.04-0.63)$ & $2.28 \pm 1.38(0.24-4.32)$ \\
Left breast & $0.89 \pm 0.57(0.31-1.41)$ & $0.24 \pm 0.10(0.16-0.39)$ & $1.74 \pm 0.83(1.05-2.96)$ & $2.51 \pm 1.27(1.45-4.35)$ & $10.27 \pm 5.08(6.37-17.7)$ \\
Right breast & $0.78 \pm 0.61(0.23-1.52)$ & $0.23 \pm 0.11(0.08-0.33)$ & $1.71 \pm 0.65(0.97-2.33)$ & $1.80 \pm 0.70(1.05-2.41)$ & $10.60 \pm 3.68(6.37-13.98)$ \\
\hline
\end{tabular}

This table assumes that imaging was considered separately from the treatment dose. In this case, a linear risk model would be applied as imaging dose is in the low dose regime. Data are given as cases per $10^{4} \mathrm{PY}$, average \pm standard deviation, range in braces 
[26]. In the clinical practice, between 10 and $15 \mathrm{~mm}$ margin are used at our department. In fact, the use of daily imaging would be expected to reduce the required margins, as the daily statistical error could be corrected before treatment and position close to the planned "ideal" position could be attained. In this case, a margin reduction would allow for better sparing of organs at risk and a possible decrease in secondary cancer risk. Therefore, the increase in dose from daily imaging might be counterbalanced by an sparing in dose due to improved positioning accuracy. Such a trade-off would be interesting to perform, but remains outside the scope of this study as a number of combinations (margin vs. imaging scenario) would need to be compared. Similar approaches have been presented for other treatment sites [11, 27]. As a rule-of-thumb, dose from $\mathrm{kV}$ imaging is relatively small and it might be expected that the positive influence of dose sparing from margin reduction would be dominant in this scenario. Regarding daily MV imaging, however, this might no longer be the case, and it is generally believed that a daily $6 \mathrm{MV}$ CBCT scenario should be avoided unless in very limited indications (e.g., direct vicinity of critical OAR and high-risk target volume).

Finally, the present study focusses on a highly vulnerable collective (children with good long-term prognosis treated with relatively large fields and wide margins), so that the resulting estimated risk can be expected to be larger than for the most frequent radiotherapy treatments (adult patients with small fields), where improved positioning accuracy and small margins achieved by daily $(\mathrm{kV})$ imaging might considerably reduce normal tissue complications without detrimentous effects on secondary cancer risk.

\section{Conclusions}

If daily imaging is required, this can be performed with less than 1 case per $10^{4} \mathrm{PY}$ additional cancer risk using $\mathrm{kV}$ $\mathrm{CBCT}$ or - if no other option exists $-6 \mathrm{MV}$ as long as planar images are taken. Depending on the geometry of the $\mathrm{X}$-ray tube (e.g., opposite to the treatment head), a further reduction on dose can be achieved for superficial organs such as the breasts by applying only a reduced-arc rotation (in our case, behind the patient's back). When analyzing secondary cancer risk from imaging modalities, this should in the best case be combined with the treatment plan, as a separate analysis of only imaging dose in the linear range leads to an overestimation of the secondary cancer risk.

\section{Abbreviations}

AP: Anterior-posterior; CBCT: Cone-beam CT; CRT: Conformal radiotherapy; $\mathrm{CT}$ : Computed tomography; DICOM: Digital Imaging and Communications in Medicine; DVH: Dose-volume histogram; EAR: Excess absolute risk; EPID: Electron portal imaging device; IBL: Imaging beam line; IGRT: Image-guided radiotherapy; LR: Left-right; MU: Monitor units; OAR: Organ at risk; OBI: On-Board Imager; PTV: Planning target volume; PY: Patient-years; RED: Risk equivalent dose; ROI: Region of interest; SI: Superior-inferior; SSD: Source-to-surface distance;
TBL: Treatment beam line; TPS: Treatment planning system; VMAT: Volumetric modulated arc therapy

\section{Acknowledgements}

We thank three anonymous reviewers for their very constructive and helpful suggestions, which we believe have greatly improved this manuscript.

\section{Funding}

The authors did not receive any funding for this study or work related to this study.

\section{Availability of data and materials}

The datasets used and/or analysed during the current study are available from the corresponding author on reasonable request.

\section{Authors' contributions}

YD, PM and FN designed the study. KB and KM performed all data handling with support by PM regarding the medical records. PR wrote and validated the Matlab code. KM, KB and YD performed the data analysis; the interpretation of the results was performed by YD, PM, FN and CR. YD wrote and revised the manuscript. All authors read and approved the final manuscript.

\section{Ethics approval and consent to participate}

All patients (and parents of the patients) gave their written informed consent to IGRT treatment. All data were retrospectively analysed in an anonymized form.

\section{Consent for publication}

Not applicable.

\section{Competing interests}

The authors declare that they have no competing interests.

\section{Publisher's Note}

Springer Nature remains neutral with regard to jurisdictional claims in published maps and institutional affiliations.

Received: 12 June 2018 Accepted: 21 August 2018

Published online: 05 September 2018

\section{References}

1. Dzierma Y, Nuesken FG, Licht NP, Ruebe C. Dosimetric properties and commissioning of cone-beam CT image beam line with a carbon target. Strahlenther Onkol. 2013;189:566-72.

2. Faddegon BA, Wu V, Pouliot J, et al. Low dose megavoltage cone beam computed tomography with an unflattened $4 \mathrm{MV}$ beam from a carbon target. Med Phys. 2008;35(12):5777-86.

3. Faddegon BA, Aubin M, Bani-Hashemi A, et al. Comparison of patient megavoltage cone beam $C T$ images acquired with an unflattened beam from a carbon target and a flattened treatment beam. Med Phys. 2010;37(4):1737-41.

4. Dzierma Y, Nuesken F, Otto W, Alaei P, Licht N, Rübe C. Dosimetry of an inline Kilovoltage imaging system and implementation in treatment planning. Int J Radiation Oncol Biol Phys. 2014;88(4):913-9.

5. Fast MF, Krauss A, Oelfke $U$, et al. Position detection accuracy of a novel linac-mounted intrafractional $x$-ray imaging system. Med Phys. 2012;39:109-18.

6. Stützel J, Oelfke U, Nill S. A quantitative image quality comparison of four different image guided radiotherapy devices. Radiother Oncol. 2008;86:20-4

7. Fast MF, Koenig T, Oelfke U, et al. Performance characteristics of a novel megavoltage cone-beam-computed tomography device. Phys Med Biol. 2012;57:N15-24

8. Dzierma Y, Beyhs M, Palm J, et al. Set-up errors and planning margins in planar and CBCT image-guided radiotherapy using three different imaging systems: a clinical study for prostate and head-and-neck cancer. Phys Med (EJMP). 2015;31(8):1055-9.

9. Dzierma Y, Ames E, Nuesken F, Palm J, Licht N, Rübe C. Image quality and dose distributions of three linac-based imaging modalities. Strahlenther Onkol. 2015;191:365-74.

10. Alcorn SR, Chen MJ, Claude L, Dieckmann K, Ermoian RP, Ford EC, et al. Practice patterns of photon and proton pediatric image guided radiation treatment: results from an international pediatric research consortium. Pract Radiat Oncol. 2014;4:336-41. 
11. Bell K, Heitfeld M, Licht N, Rübe C, Dzierma Y. Influence of daily imaging on plan quality and normal tissue toxicity for prostate cancer radiotherapy. Radiat Oncol. 2017;12:7.

12. Schneider U, Sumila M, Robotka J. Site-specific dose-response relationships for cancer induction from the combined Japanese A-bomb and Hodgkin cohorts for doses relevant to radiotherapy. Theoretical Biol Medical Modell. 2011;8:27.

13. Filippi AR, Vanoni V, Meduri B, Cozzi L, Scorsetti M, Ricardi U, Lohr F. Intensity modulated radiation therapy and second Cancer risk in adults. Int J Radiat Oncol Biol Phys. 2018;100(1):17-20.

14. Dzierma Y, Minko P, Ziegenhain R, Bell K, Buecker A, Rübe C, Jagoda P. Abdominal imaging dose in radiology and radiotherapy - phantom point dose measurements, effective dose and secondary cancer risk. Phys Med (EJMP). 2017:43:49-56.

15. Ding GX, ChW C. Radiation dose from kilovoltage cone beam computed tomography in an image-guided radiotherapy procedure. Int J Radiation Oncology Biol Phys. 2009;73(2):610-7.

16. Deng J, Chen Z, Roberts KB, Nath R. Kilovoltage imaging doses in the radiotherapy of pediatric cancer patients. Int J Radiation Oncol Biol Phys. 2012;82(5):1680-8.

17. Son K, Kim JS, Lee H, Cho S. Imaging dose of human organs from KV-CBCT in image-guided radiation therapy. Radiat Protect Dosim. 2017;175(2):194-200.

18. Hess CB, Thompson HM, Benedict SH, Seibert JA, Wong K, Vaughan AT, Chen AM. Exposure risks among children undergoing radiation therapy: considerations in the era of image guided radiation therapy. Int I Radiation Oncol Biol Phys. 2016:94(5):978-92.

19. Chargari C, Goodman KA, Diallo I, Guy J-B, Rancoule C, Cosset J-M, Deutsch E, Magne N. Risk of second cancers in the era of modern radiotherapy: does the risk/benefit analysis overcome theoretical models? Cancer Metastasis Rev. 2016;35:227-88.

20. Dörffel W, Riepenhausen M, Lüders H, Brämswig J, Schellong G. Secondary malignancies following treatment for Hodgkin's lymphoma in childhood and adolescence - a cohort study with more than 30 years' follow-up. Dtsch Arztebl Int. 2015;112:320-7.

21. Kamran SC, Berrington de Gonzalez A, Ng A, Haas-Kogan D, Viswanathan AN. Therapeutic radiation and the potential risk of second malignancies. Cancer. 2016;122:1809-21.

22. Schaapveld M, Aleman BMP, van Eggermond AM, Janus CPM, Kron ADG, et al. Second Cancer risk up to 40 years after treatment for Hodgkin's lymphoma. N Engl J Med. 2015;373(26):2499-511.

23. Zhang Y, Wu H, Chen Z, Knisely JP, Nath R, Feng Z, Bao S, Deng J. Concomitant imaging dose and Cancer risk in image guided thoracic radiation therapy. Int J Radiat Oncol Biol Phys. 2015;93(3):523-31.

24. Tamura M, Sakurai H, Mizumoto M, Kamizawa S, Murayama S, et al. Lifetime attributable risk of radiation-induced secondary cancer from proton beam therapy compared with that of intensity-modulated X-ray therapy in randomly sampled pediatric cancer patients. J Radiat Res. 2017;58(3):363-71.

25. Maraldo MV, Lundemann M, Vogelius IR, Specht L. A new method to estimate dosest o the normal tissues after past extended and involved field radiotherapy for Hodgkin lymphoma. Radiother Oncol. 2015;114:206-11.

26. Van Herk M. Errors and margins in radiotherapy. Semin Radiat Oncol. 2004; 14:52-64.

27. Bell K, Licht N, Rübe C, Dzierma Y. Image guidance and positioning accuracy in clinical practice: Influence of positioning errors and imaging dose on the real dose distribution for head and neck cancer treatment. Radiat Oncol, under review.

Ready to submit your research? Choose BMC and benefit from:

- fast, convenient online submission

- thorough peer review by experienced researchers in your field

- rapid publication on acceptance

- support for research data, including large and complex data types

- gold Open Access which fosters wider collaboration and increased citations

- maximum visibility for your research: over $100 \mathrm{M}$ website views per year

At BMC, research is always in progress.

Learn more biomedcentral.com/submissions 